\title{
RESPOSTA DO ARROZ IRRIGADO AO SUPRIMENTO DE AMÔNIO E NITRATO(1)
}

\author{
Marquel Jonas Holzschuh ${ }^{(2)}$, Humberto Bohnen ${ }^{(3)}$, Ibanor Anghinoni ${ }^{(4)}$, \\ Egon José Meurer ${ }^{(4)}$, Felipe de Campos Carmona ${ }^{(5)}$ \& Sérgio Ely Valadão \\ Gigante de Andrade Costa ${ }^{(6)}$
}

\begin{abstract}
RESUMO
No arroz cultivado sob alagamento, ocorre a elevação dos teores de $\mathrm{NH}_{4}{ }^{+}$no solo, sendo assim considerada a principal fonte de $\mathrm{N}$ para a cultura. Entretanto, o $\mathrm{O}_{2}$ transportado pelo aerênquima e liberado pelas raízes cria um ambiente favorável à nitrificação na rizosfera, determinando a formação de proporções entre amônio e $\mathrm{NO}_{3}{ }^{-}$disponíveis. Nesse caso, acredita-se que o $\mathrm{NO}_{3}{ }^{-}$pode favorecer o desenvolvimento da cultura e ao mesmo tempo evitar a toxidez por $\mathrm{NH}_{4}{ }^{+}$no solo alagado. Este trabalho foi realizado com o objetivo de avaliar o efeito de diferentes proporções dos íons $\mathrm{NH}_{4}{ }^{+} \mathrm{e} \mathrm{NO}_{3}{ }^{-}$no crescimento do arroz em solução nutritiva. $\mathrm{O}$ experimento foi realizado em casa de vegetação, no período de setembro a novembro de 2007, em solução nutritiva e substrato inerte, visando criar um meio poroso, para o crescimento radicular com as seguintes proporções de $\mathrm{NH}_{4}{ }^{+}$e $\mathrm{NO}_{3}^{-}:$100:0, 75:25 e 25:75 \% na concentração de 10,0 mmol $\mathrm{L}^{-1}$ de $\mathrm{N}$. Os baldes foram preenchidos com um substrato inerte, visando criar um meio poroso para o desenvolvimento das raízes. Foram comparados os genótipos IRGA 417 (indica) e Sasanishiki (japônica), e avaliadas a produção de biomassa, a distribuição e o comprimento de raízes e a absorção de $\mathrm{N}, \mathrm{Ca}, \mathrm{Mg}$ e $\mathrm{K}$. $\mathrm{O} \mathrm{NH}_{4}{ }^{+}$das proporções 100:0, 75:25 \% causou toxidez às plantas, porém, na maior proporção de $\mathrm{NO}_{3}^{-}$, houve redução da toxidez. $\mathrm{O}$ suprimento combinado de $\mathrm{NH}_{4}{ }^{+}$e $\mathrm{NO}_{3}{ }^{-}$aumentou a produção de biomassa em relação ao $\mathrm{NH}_{4}{ }^{+}$suprido isoladamente. $\mathrm{O}$ sistema radicular do arroz cresceu basicamente na camada de $0-10 \mathrm{~cm}$ dos cultivares testados, e o maior comprimento ocorreu no tratamento $\mathrm{NH}_{4}^{+} 75: 25 \mathrm{NO}_{3}^{-}$para a IRGA 417. $\mathrm{O} \mathrm{NH}_{4}^{+}$afetou
\end{abstract}

\footnotetext{
(1) Trabalho financiado pelo Instituto Rio Grandense do Arroz - IRGA. Recebido para publicação em julho de 2008 e aprovado em junho de 2009.

(2) Doutorando do Programa de Pós-Graduação em Ciência do Solo, Universidade Federal do Rio Grande do Sul - UFRGS. Av. Bento Gonçalves 9500, CEP 91501-970 Porto Alegre (RS). Bolsista CAPES. E-mail: marquelrs@yahoo.com.br

${ }^{(3)}$ Consultor Técnico do Instituto Rio Grandense do Arroz - IRGA. Cachoeirinha (RS). E-mail: humbertobohnen@uol.com.br

(4) Professor do Departamento de Solos, UFRGS. E-mails: ibanghi@ufrgs.br; egon_meurer@ufrgs.br

(5) Doutorando do Programa de Pós-Graduação em Ciência do Solo - UFRGS. Bolsista CAPES. E-mail: felipecamposcarmona@hotmail.com

${ }^{(6)}$ Mestrando do Programa de Pós-Graduação em Ciência do Solo, UFRGS. E-mail: sergioelycosta@hotmail.com
} 
negativamente a absorção do Ca, porém não teve efeito sobre a absorção de $\mathrm{N}, \mathrm{Mg}$ e K. O N, K e Ca total absorvidos indicam maior eficiência de absorção com o suprimento combinado das duas fontes de $\mathrm{N}$ no cultivar IRGA 417, porém sem diferença para Sasanishiki. Assim, conclui-se que o $\mathrm{NH}_{4}{ }^{+}$é tóxico para o arroz em concentrações elevadas. A presença de $\mathrm{NO}_{3}^{-}$é imprescindível para aumentar a absorção de $\mathrm{N}$, melhorando o crescimento e desenvolvimento da planta e a absorção de cátions.

Termos de indexação: nitrogênio, toxidez, Oryza sativa L., raízes.

\title{
SUMMARY: RICE GROWTH AS AFFECTED BY COMBINED AMMONIUM AND NITRATE SUPPLY
}

\begin{abstract}
In rice cultivated under flooded conditions, the anaerobic condition favors the formation of $\mathrm{NH}_{4}{ }^{+}$in the soil, and is therefore considered the main available $\mathrm{N}$ source for this crop. However, the process of $\mathrm{O}_{2}$ transport through the aerenchyma and its release by roots, create a favorable environment for nitrification in the plant rizosphere. Nitrification intensity determines the proportions between available $\mathrm{NH}_{4}{ }^{+}$and $\mathrm{NO}_{3}{ }_{3}$. In this case, it is believed that the presence of $\mathrm{NO}_{3}{ }^{-}$can favor rice growth and simultaneously avoid $\mathrm{NH}_{4}{ }^{+}$toxicity. This experiment was carried out to evaluate the effect of different proportions between $\mathrm{NH}_{4}{ }^{+}$and $\mathrm{NO}_{3}{ }^{-}$in nutrient solution on rice growth. The experiment was performed in a greenhouse, from September to November 2007, in a nutrient solution with the following $\mathrm{NH}_{4}^{+}$and $\mathrm{NO}_{3}{ }^{-}$ proportions: 100:0, 75:25 and 25:75, in a $10.0 \mathrm{mmol} \mathrm{L}^{-1} \mathrm{~N}$ concentration. The plots were fulfilled with a inert substrate to create conditions to root growth. The genotypes IRGA 417 and Sasanishiki were compared and the biomass production, root length, root distribution and the $\mathrm{N}, \mathrm{Ca}, \mathrm{Mg}$ and $\mathrm{K}$ uptake were evaluated. The presence of $\mathrm{NH}_{4}{ }^{+}$in the 100:0, 75:25 proportions resulted in plant toxicity, however, as the $\mathrm{NO}_{3}{ }^{-}$proportion increased, toxicity was reduced. The combined supply of $\mathrm{NH}_{4}^{+}$and $\mathrm{NO}_{3}^{-}$increased biomass production compared to solely $\mathrm{NH}_{4}^{+}$ supply. The rice root system of the two cultivars developed mainly in the $0-10 \mathrm{~cm}$ layer and the greatest root length was observed in the treatment $\mathrm{NH}_{4}^{+} 75: 25 \mathrm{NO}_{3}^{-}$for IRGA 417. The presence of $\mathrm{NH}_{4}^{+}$in soil solution affected negatively calcium absorption, whereas no affect was observed on $N, M g$ or $K$ absorption. The total absorbed $N, K$, and Ca indicated a higher absorption efficiency with the combined supply for IRGA 417, but for cultivar Sasanishiki no differences were verified. It was concluded that $\mathrm{NH}_{4}{ }^{+}$is toxic to rice plants, and is not the main available source of nitrogen. Nitrate is indispensable to increase the N uptake, normal plant growth and total cation absorption.
\end{abstract}

Index terms: nitrogen, toxicity, Oryza sativa L., roots.

\section{INTRODUÇÃO}

O suprimento de $\mathrm{N}$ e a capacidade de absorção pelas plantas são determinantes para obter elevados rendimentos na cultura do arroz cultivado sob alagamento. Nesse ambiente, as perdas de $\mathrm{N}$ correspondem a aproximadamente $50 \%$ do total fornecido via fertilizantes, tornando-se uma prática agrícola economicamente dispendiosa e potencialmente poluente. $\mathrm{O}$ suprimento, a forma preferencialmente absorvida e a assimilação de $\mathrm{N}$ pelas plantas têm sido amplamente estudados, gerando grandes avanços na área, porém com divergências sobre alguns aspectos (Britto et al., 2001; Tobin \& Yamaya, 2001; Britto \& Kronzucker, 2002; Forde, 2002). No arroz irrigado, ainda persistem dúvidas sobre sua disponibilidade e a forma preferencial absorvida pela planta principalmente por- que, no solo alagado, o ambiente anaeróbio do solo propicia a elevação da concentração de $\mathrm{NH}_{4}{ }^{+}$oriunda de formas orgânicas e inorgânicas (Ponnamperuma, 1972) sendo, nesse caso, considerada a principal fonte de $\mathrm{N}$ mineral disponível para o arroz (Wang et al., 1993; Kronzucker et al., 2000). Por outro lado, o $\mathrm{NO}_{3}{ }^{-}$ é considerado a principal fonte de $\mathrm{N}$ para a maioria das plantas cultivadas, principalmente em solos aerados (Britto \& Kronzucker, 2002; Epstein \& Bloom, 2006). No solo alagado, a disponibilidade de compostos oxidados que servem como aceptores de elétrons para os microrganismos anaeróbios determina a instabilidade do $\mathrm{NO}_{3}{ }^{-}$, sendo rapidamente desnitrificado e perdido para a atmosfera (Ponnamperuma, 1972).

Gigon \& Rorison (1972), Britto \& Kronzucker (2002) e Kronzucker et al. (2000) relatam que o N fornecido na forma de $\mathrm{NH}_{4}{ }^{+}$causa uma série de 
distúrbios fisiológicos no interior e no exterior das células, caracterizando toxidez para as plantas. Sintomas de toxidez por $\mathrm{NH}_{4}^{+}$foram observados em várias espécies, entre elas estão tomate e ervilha (Claassen \& Wilcox, 1974), batata (Cao \& Tibbits, 1998), cevada (Britto et al., 2001), feijão (Zhu et al., 2000) e beterraba (Harada et al., 1968). A toxidez ao $\mathrm{NH}_{4}{ }^{+}$é apontada como variável entre as espécies, podendo ser tolerado por algumas, como tem sido atribuído à cultura do arroz (Wang et al., 1993; Kronzucker et al., 2000; Kronzucker et al., 2001; Britto \& Kronzucker, 2002). No entanto, mesmo espécies consideradas tolerantes podem apresentar sintomas de toxidez, principalmente quando associados a baixas concentrações de $\mathrm{K}^{+}, \mathrm{Ca}^{2+} \mathrm{e} \mathrm{Mg}^{2+}$ ou sob concentrações elevadas de N (Holldampf \& Barker, 1993; Speer \& Kaiser, 1994; Britto \& Kronzucker, 2002). Os efeitos da toxidez por $\mathrm{NH}_{4}{ }^{+}$normalmente resultam em redução no crescimento de raízes e da parte aérea das plantas e em menor quantidade de $\mathrm{N}$ absorvido. Em casos severos, pode ocasionar a morte da planta (Gigon \& Rorison, 1972)

Na literatura, várias são as hipóteses formuladas na tentativa de explicar os processos envolvidos na absorção e assimilação do $\mathrm{N}$ e os efeitos sobre o metabolismo da planta causados pelo $\mathrm{NH}_{4}{ }^{+}$e pelo $\mathrm{NO}_{3}{ }^{-}$ (Britto \& Kronzucker, 2002). Entre eles estão o efeito do $\mathrm{pH}$ na manutenção do gradiente de potencial eletroquímico na membrana (Wang et al., 1993; Britto et al., 2001), o balanço de cargas na célula (Cramer \& Lewis, 1993) e o gasto energético para a assimilação dos íons e alocação de fotoassimilados (Murphy \& Lewis, 1987). De acordo com Forde (2000), Kronzucker et al. (2000) e Forde (2002), além do $\mathrm{NO}_{3}{ }^{-}$no meio de crescimento ser importante como nutriente, atua como um sinalizador de curta e longa distância para desencadear processos hormonais que determinam a expressão de genes que codificam proteínas transportadores de $\mathrm{NH}_{4}^{+}$(AMTs) e $\mathrm{NO}_{3}^{-}$(NRTs), resultando num efeito estimulante ou sinérgico sobre a absorção de $\mathrm{NH}_{4}{ }^{+}$e mesmo sobre a absorção de $\mathrm{NO}_{3}{ }^{-}$. Como no solo alagado a instabilidade do $\mathrm{NO}_{3}$ determina que sua concentração seja próxima de zero, persistem dúvidas sobre a falta e, ou, presença deste elemento no crescimento e desenvolvimento do arroz.

No solo alagado, a falta de $\mathrm{O}_{2}$ determina a formação de espaços porosos no córtex de raízes e colmo do arroz (aerênquima) pelo qual o $\mathrm{O}_{2}$ é transportado até a zona de crescimento das raízes suprindo sua necessidade fisiológica (Colmer, 2003; Malik et al., 2003). $\mathrm{O} \mathrm{O}_{2}$ transportado via aerênquima é, em parte, liberado na rizosfera do arroz devido à permeabilidade das raízes e o gradiente de $\mathrm{O}_{2}$ criado entre o solo reduzido e a raiz (Armstrong, 1979; Colmer, 2003). Nessa condição, ocorre a formação de um ambiente oxidado na rizosfera que determina uma série de reações químicas, bem como uma condição favorável para o desenvolvimento de microrganismos aeróbios, incluindo os nitrificadores. Assim, atenção tem sido dada à possibilidade da transformação do $\mathrm{NH}_{4}{ }^{+}$do solo em $\mathrm{NO}_{3}{ }^{-}$na rizosfera do arroz, sugerindo que esse mecanismo seja responsável por fornecer as duas formas de $\mathrm{N}$ de forma combinada e em proporções variáveis em função da intensidade da liberação de $\mathrm{O}_{2}$ pela raiz (Kludze et al., 1993; Kirk \& Kronzucker, 2005; Duan et al., 2006). De acordo com Kirk (2001) e Kronzucker et al. (2000), a suposta tolerância ao $\mathrm{NH}_{4}{ }^{+}$pelo arroz pode estar associada à nitrificação na rizosfera, porém pouco se sabe sobre a intensidade da nitrificação e a proporção entre $\mathrm{NH}_{4}{ }^{+} \mathrm{e} \mathrm{NO}_{3}{ }^{-}$resultante. Trabalhos recentes como os de Duan et al. (2006) e Duan et al. (2007) relatam que plantas de arroz cultivadas sob proporções variáveis de $\mathrm{NH}_{4}{ }^{+} \mathrm{e} \mathrm{NO}_{3}{ }^{-}$ mostraram-se mais eficientes em absorver $\mathrm{N}$ em comparação às mesmas formas fornecidas isoladamente e que o efeito sobre a absorção e rendimento pode variar entre cultivares de uma mesma espécie e entre estádios de desenvolvimento.

A intensidade da nitrificação tem sido relacionada com características morfológicas das raízes. De acordo com Guy \& Kirk (2003) e Smet et al. (2006), as raízes laterais são mais permeáveis ao $\mathrm{O}_{2}$, podendo favorecer a nitrificação. Por outro lado, elas também são mais ativas e respondem pela maior parte da absorção de água e de nutrientes. No solo alagado, as raízes do arroz são compostas basicamente por raízes adventícias que surgem da base da planta e se distribuem basicamente nos primeiros centímetros do perfil do solo (Lopes et al., 1994; Abichequer, 2004), explorando menor volume de solo, devido às condições adversas impostas pelo ambiente anaeróbio, podendo limitar a absorção de alguns nutrientes principalmente em profundidade. Portanto, como ainda persistem dúvidas sobre a proporção entre $\mathrm{NH}_{4}{ }^{+}$e $\mathrm{NO}_{3}{ }^{-}$ resultante da nitrificação que promove o maior aproveitamento do $\mathrm{N}$, torna-se necessário, num primeiro momento, testar o efeito de proporções entre amônio $\mathrm{NH}_{4}{ }^{+}$e $\mathrm{NO}_{3}{ }^{-}$sobre o crescimento e desenvolvimento do arroz em condições controladas, na ausência da interferência das reações químicas e em processos biológicos que ocorrem no solo. Assim, este trabalho foi realizado com o objetivo de avaliar o crescimento do arroz submetido à aplicação combinada de $\mathrm{NH}_{4}{ }^{+}$e de $\mathrm{NO}_{3}{ }^{-}$em solução nutritiva.

\section{MATERIAL E MÉTODOS}

O experimento foi realizado em casa de vegetação do Departamento de Solos da Universidade Federal do Rio Grande do Sul (Porto Alegre - RS) no período de setembro a novembro de 2007. As unidades experimentais (UEs) foram constituídas de recipientes de polietileno (vasos) com capacidade para $10 \mathrm{~L}$. Como substrato, foi utilizado poliestireno cristal granulado, material inerte e de densidade superior à da água, objetivando criar um meio no qual ocorra crescimento e distribuição do sistema radicular do arroz semelhante ao cultivado em condições naturais. 
O experimento foi conduzido em solução nutritiva e os tratamentos constaram das seguintes proporções entre $\mathrm{NH}_{4}{ }^{+}$e $\mathrm{NO}_{3}{ }^{-}: 100: 0,75: 25$ e 25:75 \%. Para compor os tratamentos, foram utilizadas as seguintes fontes: $\mathrm{NH}_{4} \mathrm{NO}_{3} \quad\left(\mathrm{NH}_{4}\right)_{2} \mathrm{SO}_{4}, \mathrm{Ca}\left(\mathrm{NO}_{3}\right)_{2} \cdot \mathrm{H}_{2} \mathrm{O}$, $\mathrm{Mg}\left(\mathrm{NO}_{3}\right)_{2}, \mathrm{KNO}_{3}, \mathrm{NH}_{4} \mathrm{H}_{2} \mathrm{PO}_{4},\left(\mathrm{NH}_{4}\right)_{2} \mathrm{HPO}_{4}, \mathrm{NH}_{4} \mathrm{Cl}$, $\mathrm{MgSO}_{4} \cdot 7 \mathrm{H}_{2} \mathrm{O}, \mathrm{CaSO}_{4} \cdot 2 \mathrm{H}_{2} \mathrm{O}, \mathrm{KCle} \mathrm{KH}{ }_{2} \mathrm{PO}_{4}$ (Quadro 1).

A solução contendo micronutrientes foi composta por: $\mathrm{Mn}-\left(\mathrm{MnSO}_{4} \mathrm{H}_{2} \mathrm{O}(0,0047 \mathrm{mmol} \mathrm{L}-1), \mathrm{Cu}-\right.$ $\left(\mathrm{CuSO}_{4} 5 . \mathrm{H}_{2} \mathrm{O}\right)\left(0,0047 \mathrm{mmol} \mathrm{L}^{-1}\right), \mathrm{Zn}\left(\mathrm{ZnSO}_{4} 7 . \mathrm{H}_{2} \mathrm{O}\right)$ $\left(0,0015 \mathrm{mmol} \mathrm{L}^{-1}\right), \mathrm{B}-\left(\mathrm{H}_{3} \mathrm{BO}_{3}\right)\left(0,023 \mathrm{mmol} \mathrm{L}^{-1}\right), \mathrm{Mo}$ $-\left(\mathrm{NaMoO}_{4} 2 \mathrm{H}_{2} \mathrm{O}\right)\left(0,00011 \mathrm{mmol} \mathrm{L}^{-1}\right)$ e Fe-EDTA $(\mathrm{Fe}$ $\left.-0,5 \mathrm{mg} \mathrm{L}^{-1}\right)$.

Os genótipos de arroz avaliados foram o IRGA 417, pertencente ao grupo moderno (indica) e Sasanishiki (japônica). As sementes foram previamente embebidas em água durante $24 \mathrm{~h}$ e, posteriormente, seis foram colocadas para germinar diretamente em cada vaso, no substrato, contendo somente água destilada. Aos quatro dias após a emergência (DAE), foi iniciado o fornecimento da solução nutritiva. Cada vaso recebeu 2,5 L de solução nutritiva. Sete dias após a emergência, momento em que as plantas iniciavam a emissão da terceira folha, foi realizado um desbaste, mantendo-se uma planta em cada vaso. Os vasos foram mantidos cobertos com uma lâmina de poliestireno expandido (isopor ${ }^{\circledR}$ ) com espessura de $2,5 \mathrm{~cm}$ com um orifício central para dar suporte às plantas, evitar a entrada direta de luz e reduzir a evaporação da água. As soluções foram trocadas seis vezes durante a condução do experimento sob o critério de manter o $\mathrm{pH}$ próximo de 6,0 , semelhante ao normalmente encontrado em solos alagados (Ponnamperuma, 1972) ou quando houve uma redução no nível de solução causada pela evapotranspiração.

As plantas foram colhidas $38 \mathrm{DAE}$, cortando-as na base. A solução foi drenada e os vasos juntamente com o substrato e as raízes foram secas em estufa a $60{ }^{\circ} \mathrm{C}$, com o objetivo de manter a arquitetura das raízes originalmente formadas. A parte aérea e as

Quadro 1. Concentração de nutrientes da solução nutritiva que compõe as proporções de $\mathrm{N}-\mathrm{NH}_{4}{ }^{+}$ e N-NO${ }_{3}^{-}$

\begin{tabular}{|c|c|c|c|}
\hline \multirow{2}{*}{ Nutriente } & \multicolumn{3}{|c|}{ Proporção (\%) } \\
\hline & $\begin{array}{c}\mathrm{NH}_{4}^{+} \\
\text {100:0 } \mathrm{NO}_{3}^{-}\end{array}$ & $\begin{array}{c}\mathrm{NH}_{4}^{+} \\
75: 25 \mathrm{NO}_{3}^{-}\end{array}$ & $\begin{array}{c}\mathrm{NH}_{4}^{+} \\
\text {25:75 } \mathrm{NO}_{3}\end{array}$ \\
\hline & & $-\mathrm{mmol} \mathrm{L}^{-1}$ & \\
\hline $\mathrm{N}$ & 10,0 & 10,0 & 10,0 \\
\hline $\mathrm{P}$ & 1,0 & 1,0 & 1,0 \\
\hline $\mathrm{K}$ & 2,0 & 2,0 & 3,0 \\
\hline $\mathrm{Ca}$ & 1,0 & 1,0 & 1,5 \\
\hline $\mathrm{Mg}$ & 1,0 & 1,0 & 1,5 \\
\hline $\mathrm{S}$ & 6,0 & 4,0 & 1,0 \\
\hline $\mathrm{Cl}$ & 2,0 & 2,0 & 1,0 \\
\hline
\end{tabular}

raízes foram secas em estufa de ar forçado a $60{ }^{\circ} \mathrm{C}$ até peso constante para a determinação da matéria seca. As raízes foram cortadas em intervalos de $5 \mathrm{~cm}$ e na medida em que se desenvolveram em profundidade, posteriormente, coradas com uma solução de azul de bromotimol e $\mathrm{NaOH} 0,1 \mathrm{~mol} \mathrm{~L}^{-1}$. Para cada camada de $5 \mathrm{~cm}$, as raízes foram dispostas sobre um filme transparente e escaneadas. As imagens digitais foram ajustadas com o software Photoshop ${ }^{\circledR}$, para posterior determinação do comprimento das raízes com o auxílio do software SIARCS ${ }^{\circledR}$ 3.0, conforme Crestana et al. (1994).

A parte aérea e as raízes foram moídas em micromoinho e as amostras submetidas à digestão ácida para posterior determinação do teor de N, K, Ca e $\mathrm{Mg}$ (Tedesco et al., 1995). Os vasos foram dispostos obedecendo a um delineamento inteiramente casualizado, com três repetições, totalizando 18 vasos. Os resultados foram submetidos à análise da variância $(\mathrm{p}<0,05)$ e à comparação entre médias dos tratamentos pelo teste do DMS $(p<0,05)$.

\section{RESULTADOS E DISCUSSÃO}

\section{Produção de biomassa e efeito dos íons $\mathrm{NH}_{4}{ }^{+}$ e $\mathrm{NO}_{3}{ }^{-}$}

Os genótipos diferenciaram-se entre si quanto à produção da parte aérea e total, exceto para as raízes no tratamento $\mathrm{NH}_{4}{ }^{+}$100:0 $\mathrm{NO}_{3}{ }^{-}$(Quadro 2). O cultivar IRGA 417 foi superior ao Sasanishiki, evidenciando o contraste genético dos cultivares. Quando comparadas as proporções entre $\mathrm{NH}_{4}{ }^{+}{\mathrm{e} \mathrm{NO}_{3}}_{3}$, a maior produção de biomassa de parte aérea, raiz e total no cultivar IRGA 417 foi obtida no tratamento $\mathrm{NH}_{4}{ }^{+}$75:25 $\mathrm{NO}_{3}^{-}$(Quadro 2). Para o cultivar Sasanishiki, não houve diferença na produção de biomassa; entretanto, a variação segue o mesmo comportamento observado para o cultivar IRGA 417 em cada proporção entre $\mathrm{NH}_{4}{ }^{+}$e $\mathrm{NO}_{3}{ }^{-}$. Mesmo que as diferenças tenham sido pouco expressivas, elas indicam que o suprimento combinado de $\mathrm{NH}_{4}{ }^{+} \mathrm{e} \mathrm{NO}_{3}{ }^{-}$ proporcionou melhor crescimento das plantas do que $\mathrm{o} \mathrm{NH}_{4}{ }^{+}$suprido isoladamente, como também observado por Kronzucker et al. (1999), Duan et al. (2006) e Duan et al. (2007).

As plantas de ambos os cultivares apresentaram sintomas de toxidez em todos os tratamentos. No cultivar IRGA 417, a toxidez foi mais expressiva em relação ao Sasanishiki. No tratamento $\mathrm{NH}_{4}{ }^{+}$100:0 $\mathrm{NO}_{3}{ }^{-}$, os sintomas eram visíveis aos $25 \mathrm{DAE}$ nos dois cultivares, o que causou menor produção de biomassa nesse tratamento (Quadro 2). Os sintomas manifestaram-se, em primeiro lugar, nas folhas mais velhas na forma de manchas cloróticas, evoluindo para a necrose da folha da bainha para o centro. Isso sugere que a toxidez por $\mathrm{NH}_{4}{ }^{+}$está relacionada a um efeito acumulativo na parte aérea (Britto \& Kronzucker, 
Quadro 2. Produção de biomassa da parte aérea, raízes e relação raiz/parte área de cultivares de arroz em função de proporções de $\mathrm{N}_{-} \mathrm{NH}_{4}{ }^{+} \mathrm{e} \mathrm{N}-\mathrm{NO}_{3}{ }^{-}$na solução

\begin{tabular}{|c|c|c|c|c|}
\hline Proporção & Parte aérea & Raiz & Total & Raiz/parte aérea \\
\hline$\%$ & \multicolumn{4}{|c|}{$\begin{array}{c}\text { g/planta } \\
\text { IRGA } 417\end{array}$} \\
\hline $\mathrm{NH}_{4}^{+} 100: 0 \mathrm{NO}_{3}^{-}$ & $1,50 \mathrm{~b}^{(1)} \mathrm{A}^{(2)}$ & $0,38 \mathrm{cA}$ & $1,88 \mathrm{bA}$ & $0,26 \mathrm{bB}$ \\
\hline $\mathrm{NH}_{4}^{+} 75: 25 \mathrm{NO}_{3}^{-}$ & $2,27 \mathrm{aA}$ & $0,69 \mathrm{aA}$ & $2,95 \mathrm{aA}$ & $0,30 \mathrm{abA}$ \\
\hline \multirow[t]{2}{*}{$\mathrm{NH}_{4}^{+} 25: 75 \mathrm{NO}_{3}^{-}$} & $1,66 \mathrm{bA}$ & $0,52 \mathrm{bA}$ & $2,18 \mathrm{bA}$ & $0,31 \mathrm{aA}$ \\
\hline & \multicolumn{4}{|c|}{ Sasanishiki } \\
\hline $\mathrm{NH}_{4}^{+} 100: 0 \mathrm{NO}_{3}^{-}$ & $0,99 \mathrm{aB}$ & $0,33 \mathrm{aA}$ & $1,32 \mathrm{aB}$ & $0,33 \mathrm{abA}$ \\
\hline $\mathrm{NH}_{4}^{+} 75: 25 \mathrm{NO}_{3}^{-}$ & $1,35 \mathrm{aB}$ & $0,39 \mathrm{aB}$ & $1,74 \mathrm{aB}$ & $0,29 \mathrm{bA}$ \\
\hline $\mathrm{NH}_{4}^{+} 25: 75 \mathrm{NO}_{3}^{-}$ & $1,09 \mathrm{aB}$ & $0,37 \mathrm{aB}$ & $1,45 \mathrm{aB}$ & $0,34 \mathrm{aA}$ \\
\hline
\end{tabular}

\footnotetext{
(1) Médias seguidas por letras minúsculas iguais dentro de cada cultivar não diferem entre si pelo teste do DMS ( $\mathrm{p}>0,05$ ).

${ }^{(2)}$ Médias seguidas por letras maiúsculas iguais entre cultivares não diferem entre si pelo teste do DMS ( $\left.\mathrm{p}>0,05\right)$.
}

2005). Sintomas semelhantes manifestaram nos demais tratamentos, porém com baixa intensidade e somente aos 33 e 36 DAE para as proporções $\mathrm{NH}_{4}{ }^{+}$ 75:25 $\mathrm{NO}_{3}^{-}$e $\mathrm{NH}_{4}{ }^{+}$25:75 $\mathrm{NO}_{3}^{-}$respectivamente. Embora possam ser encontradas concentrações de até 20,0 $\mathrm{mmol} \mathrm{L}^{-1}$ de $\mathrm{NH}_{4}{ }^{+}$em solos agricultáveis (Wolt, 1994), a concentração de $10,0 \mathrm{mmol} \mathrm{L}^{-1}$ de N utilizada no experimento pode ter sido a causa da toxidez mesmo nas proporções contendo nitrato, o que pode ter ocorrido porque a solução era substituída constantemente e, dessa forma, a concentração era mantida praticamente constante durante o período de cultivo, ao contrário do que acontece no cultivo em campo, em que as interferências do ambiente determinam variações na concentração, principalmente devido às perdas.

Conforme Wang et al. (1994), nas concentrações entre 1 e $40 \mathrm{mmol} \mathrm{L}^{-1}$, a absorção ocorre predominantemente por transportadores de baixa afinidade (Low Affinity Transport Systems - LATS), de maneira passiva, o que afeta o controle de entrada do $\mathrm{NH}_{4}{ }^{+}$na célula, causando seu acúmulo. De acordo com Britto \& Kronzucker (2002), a assimilação de $\mathrm{NH}_{4}{ }^{+}$ocorre predominantemente nas raízes, ao contrário do $\mathrm{NO}_{3}{ }^{-}$ que ocorre na parte aérea. Nesse caso, quando o controle da entrada de $\mathrm{NH}_{4}{ }^{+}$pela membrana plasmática é afetado e maiores quantidades são transportadas para a parte aérea, pode ocorrer o acúmulo e, consequentemente, toxidez. O maior crescimento da parte aérea do cultivar IRGA 417 em relação ao Sasanishiki sugere a ocorrência de maior taxa transpiratória devido à maior área foliar, o que, consequentemente, determina maior absorção de água. O maior fluxo de água pela planta acarretará na maior absorção de nutrientes, principalmente os que são transportados por canais menos seletivos na membrana plasmática. Por isso, mesmo nas menores proporções, a concentração de $\mathrm{NH}_{4}{ }^{+}$deve ter sido suficientemente elevada para causar toxidez. $\mathrm{O}$ comportamento acumulativo desse elemento nas células e sua relação com a toxidez foram também observadas por Britto et al. (2001), que encontraram concentrações de $\mathrm{NH}_{4}{ }^{+}$superiores a $100,0 \mathrm{mmol} \mathrm{L}^{-1}$ no citosol de cevada e arroz sob concentrações externas de $10,0 \mathrm{mmol} \mathrm{L}^{-1}$ de $\mathrm{NH}_{4}{ }^{+}$. Sintomas de toxidez semelhantes também foram relatados por Gigon \& Rorison (1972); Britto \& Kronzucker (2002) e Kronzucker et al. (2000) em diversas culturas. Para Kosengarten et al. (1997), um dos possíveis mecanismos causadores da toxidez pelo $\mathrm{NH}_{4}{ }^{+}$é a acidificação na rizosfera e, principalmente, no interior das células, ocasionado pela absorção de cátions $\left(\mathrm{NH}_{4}{ }^{+}\right)$ e liberação de hidrogênio $\left(\mathrm{H}^{+}\right)$. A acidificação do meio resulta na hiperpolarização da membrana, ocasionando distúrbios em diversos processos metabólicos (Wang et al., 1993; Britto et al., 2001).

Um sintoma característico observado quando há toxidez por $\mathrm{NH}_{4}^{+}$é a redução da relação raiz/parte aérea (Haynes \& Goh, 1978). Na IRGA 417, a menor relação raiz/parte aérea ocorreu quando o $\mathrm{NH}_{4}{ }^{+}$foi fornecido isoladamente. Em Sasanishiki, como os sintomas de toxidez foram menos expressivos, isso não ocorreu (Quadro 2). Conforme Britto \& Kronzucker (2002), ocorre uma inibição do crescimento do sistema radicular devido ao aumento das taxas respiratórias pelo estresse causado pelo $\mathrm{NH}_{4}^{+}$, resultando em maior gasto energético. Plantas supridas com $\mathrm{NH}_{4}{ }^{+}$ aumentam a demanda por fotoassimilados que são alocados da parte aérea para as raízes, necessários para que ocorra a assimilação do $\mathrm{NH}_{4}{ }^{+}$(Murphy \& Lewis, 1987). Assim, a partição dos fotoassimilados entre a parte aérea e as raízes resulta no menor crescimento da parte aérea, afetando o crescimento e desenvolvimento da planta. Kronzucker et al. (2000) e Britto et al. (2001) relatam que a incapacidade de controlar o influxo de $\mathrm{NH}_{4}{ }^{+}$na célula ativa um mecanismo de efluxo desse íon. Tal mecanismo tem sido denominado ciclagem fútil por esses autores e o efeito resultante seria um elevado gasto energético necessário para bombear o $\mathrm{NH}_{4}{ }^{+}$para fora da célula. 
Conforme esses autores, aproximadamente $80 \%$ do $\mathrm{NH}_{4}{ }^{+}$absorvido pode sofrer efluxo por esse processo e o elevado consumo de ATP resultante acarreta em elevada respiração pelas raízes, determinando redução no seu crescimento.

Nos dois cultivares, o tratamento com maior proporção de $\mathrm{NO}_{3}{ }^{-}$apresentou a maior relação raizl parte aérea (Quadro 2). Isso porque, além de estar sob influência de menor concentração de $\mathrm{NH}_{4}{ }^{+}, \mathrm{o} \mathrm{NO}_{3}{ }^{-}$ é apontado como sinalizador para expressão de genes relacionados com a formação de raízes (Smet et al., 2006), absorção e assimilação de $\mathrm{NH}_{4}{ }^{+}$e $\mathrm{NO}_{3}{ }^{-} \mathrm{e}$ redução do $\mathrm{NO}_{3}{ }^{-}$(Forde, 2002). A presença de $\mathrm{NO}_{3}{ }^{-}$ também é importante para manter o balanço de cargas na célula, evitando a despolarização da membrana (Wang et al., 1993). Além do efeito do $\mathrm{NH}_{4}{ }^{+}$e do $\mathrm{NO}_{3}{ }^{-}$ no crescimento das raízes, deve-se considerar o efeito sobre a parte aérea. Neste caso, a menor produção de biomassa da parte aérea no tratamento com maior proporção de $\mathrm{NO}_{3}^{-}$(25:75) contribuiu para elevar a relação (Quadro 2). Para Britto \& Kronzucker (2002) e Kronzucker et al. (2001), além do gasto energético resultante da alocação de fotoassimilados, a inibição do crescimento da parte aérea também está relacionada com o maior gasto energético requerido para assimilação do $\mathrm{NO}_{3}^{-}$(12 ATPs) comparado ao $\mathrm{NH}_{4}{ }^{+}(2 \mathrm{ATPs})$.

\section{Distribuição e comprimento de raízes}

Os cultivares apresentaram um padrão semelhante de distribuição de raízes entre os tratamentos nas profundidades avaliadas (Quadro 3). De modo geral, as raízes cresceram basicamente na camada de 0$10 \mathrm{~cm}$, perfazendo em torno de $70 \%$ para a IRGA 417 e acima de $85 \%$ para Sasanishiki (Quadro 3). O cultivar IRGA 417 apresentou maior aprofundamento do sistema radicular, chegando até $20 \mathrm{~cm}$, ao contrário de Sasanishiki, que ficou restrito à camada de $15 \mathrm{~cm}$ (Quadro 3). Embora a avaliação compreenda um período de crescimento em que o sistema radicular não está totalmente desenvolvido, o comportamento indica um crescimento superficial para ambos os cultivares. Comportamento semelhante também foi observado por Abichequer (2004) testando cultivares de arroz em solução nutritiva e em solo. De acordo com Lopes et al. (1994), o crescimento do sistema radicular do arroz é fortemente afetado pelo regime de água e pelas condições do solo. Antes da inundação, o arroz tende a aprofundar o sistema radicular, principalmente em busca de água e, após a inundação, ocorre crescimento superficial, principalmente devido à redução nos níveis de $\mathrm{O}_{2}$ em profundidade e pelos produtos da redução no solo.

Para o comprimento total de raízes houve diferença entre os cultivares em cada tratamento, sendo o IRGA 417 superior ao Sasanishiki (Quadro 3). Entre os tratamentos, não houve diferença de comprimento de raízes para o cultivar Sasanishiki; no entanto, para o IRGA 417, o tratamento $\mathrm{NH}_{4}{ }^{+} 75: 25 \mathrm{NO}_{3}{ }^{-}$apresentou um comprimento de raízes 47 e $30 \%$ superior nos tratamentos $\mathrm{NH}_{4}{ }^{+}$100:0 $\mathrm{NO}_{3}{ }^{-}$e $\mathrm{NH}_{4}{ }^{+} 25: 75 \mathrm{NO}_{3}{ }^{-}$ respectivamente. $\mathrm{O}$ sistema radicular do arroz que cresce nas camadas superficiais é composto basicamente por raízes finas secundárias, terciárias, etc., o que aumenta substancialmente a área superficial de raízes e o seu comprimento, contribuindo para a maior absorção de nutrientes (Lopes et al., 1994). O conhecimento do comportamento da distribuição e, ou, extensão do sistema radicular de cultivares de arroz dá suporte para estudos sobre o manejo de aplicação de adubos e corretivos,

Quadro 3. Distribuição do sistema radicular de cultivares de arroz em função do suprimento combinado de $\mathrm{N}-\mathrm{NH}_{4}{ }^{+}$e N-NO${ }_{3}^{-}$na solução

\begin{tabular}{|c|c|c|c|}
\hline \multirow{2}{*}{ Camada } & \multicolumn{3}{|c|}{ Proporção (\%) } \\
\hline & $\mathrm{NH}_{4}^{+} 100: 0 \mathrm{NO}_{3}^{-}$ & $\mathrm{NH}_{4}^{+} 75: 25 \mathrm{NO}_{3}^{-}$ & $\mathrm{NH}_{4}^{+} 25: 75 \mathrm{NO}_{3}^{-}$ \\
\hline $\mathrm{cm}$ & & $\begin{array}{c}\text { Comprimento (m) } \\
\text { IRGA } 417\end{array}$ & \\
\hline $\begin{array}{c}0-5 \\
5-10 \\
10-15 \\
15-20\end{array}$ & $\begin{array}{c}9,2(27)^{(1)} \\
14,9(43) \\
9,1(26) \\
1,4(4)\end{array}$ & $\begin{array}{c}13,2(24) \\
23,1(42) \\
16,0(29) \\
2,5(5)\end{array}$ & $\begin{array}{c}11,9(30) \\
16,9(43) \\
10,0(25) \\
0,7(2)\end{array}$ \\
\hline Total & $34,6 \mathrm{bA}^{(2)}$ & $54,8 \mathrm{aA}$ & $39,4 \mathrm{bA}$ \\
\hline $\begin{array}{c}0-5 \\
5-10 \\
10-15 \\
15-20\end{array}$ & $\begin{array}{c}11,9(39) \\
14,4(47) \\
4,1(14) \\
0,0\end{array}$ & $\begin{array}{c}\text { Sasanishiki } \\
13,6(46) \\
12,2(42) \\
3,6(12) \\
0,0\end{array}$ & $\begin{array}{r}13,1(52) \\
9,5(38) \\
2,7(11) \\
0,0\end{array}$ \\
\hline Total & $30,4 \mathrm{aA}$ & $29,4 \mathrm{aB}$ & $25,3 \mathrm{aB}$ \\
\hline
\end{tabular}

${ }^{(1)}$ Valores entre parênteses correspondentes aos percentuais de raízes em cada profundidade. ${ }^{(2)}$ Letras minúsculas comparam tratamentos e letras maiúsculas comparam cultivares pelo teste do DMS $(\mathrm{p}<0,05)$. 
principalmente em relação à camada de solo explorado, diferentemente do manejo adotado em solos com culturas de sequeiro onde ocorre maior aprofundamento. O crescimento superficial de raízes em arroz pode influenciar na absorção de nutrientes, principalmente de $\mathrm{N}$, visto que as adubações de cobertura são feitas em superfície. Neste caso, é importante considerar que, em cultivo no campo, há uma fina camada superficial do solo alagado oxidada, onde ocorre o desenvolvimento de microrganismos aeróbios, entre eles os nitrificadores (Ponnamperuma, 1972). Desta forma, a nitrificação resultante de toda área superficial da lavoura pode ser importante fonte de $\mathrm{NO}_{3}{ }^{-}$para as raízes superficiais do arroz, impedindo que o $\mathrm{NO}_{3}^{-}$alcance as camadas reduzidas do solo e, consequentemente, seja desnitrificado.

\section{Teor de nutrientes no tecido}

O cultivar IRGA 417 apresentou maior teor de $\mathrm{N}$ na biomassa da parte aérea com o suprimento combinado de $\mathrm{NH}_{4}{ }^{+}$e $\mathrm{NO}_{3}{ }^{-}$(Quadro 4). Já para o cultivar Sasanishiki, o tratamento $\mathrm{NH}_{4}{ }^{+} 75: 25 \mathrm{NO}_{3}{ }^{-}$ propiciou maior teor de $\mathrm{N}$ na parte aérea em relação aos demais. Ambos os cultivares não apresentaram diferenças no teor de $\mathrm{N}$ na raiz (Quadro 4). Entre os cultivares, o IRGA 417 apresentou maior teor de N no tecido da parte aérea do que o Sasanishiki, e nas raízes o Sasanishiki foi superior. O maior teor de $\mathrm{N}$ na parte aérea com o suprimento combinado, analisado juntamente com a intensidade dos sintomas de toxidez apresentados em cada tratamento, indica que o $\mathrm{NO}_{3}{ }^{-}$ é determinante para o crescimento e desenvolvimento normal do arroz. Dessa forma, como no solo alagado ocorre o aumento da concentração de $\mathrm{NH}_{4}{ }^{+}$e o arroz se desenvolve normalmente, é possível que a nitrificação na rizosfera e, ou, na superfície do solo seja responsável por fornecer uma quantidade de $\mathrm{NO}_{3}{ }^{-}$ adequada para promover um crescimento normal da planta e evitar a toxidez ao $\mathrm{NH}_{4}{ }^{+}$, conforme sugerem Britto \& Kronzucker (2002), Guy \& Kirk (2003), Kronzucker et al. (2000), Duan et al. (2006) e Duan et al. (2007).

De acordo com Holldampf \& Barker (1993); Speer \& Kaiser (1994); Troelstra et al. (1995), era de se esperar que houvesse redução na concentração de $\mathrm{K}$, $\mathrm{Ca}$ e $\mathrm{Mg}$ nos tratamentos com maiores percentuais de $\mathrm{NH}_{4}{ }^{+}$, devido à competição por sítios catiônicos menos seletivos na membrana plasmática. Entretanto, neste experimento não foi observado esse comportamento de maneira clara. Para a absorção de K, não houve diferenças entre os tratamentos no cultivar IRGA 417, entretanto, para o Sasanishiki, as plantas cultivadas com $\mathrm{NH}_{4}{ }^{+}$isolado apresentaram maior teor de $\mathrm{K}$ na parte aérea e menor nas raízes em relação aos demais tratamentos (Quadro 4). Entre os cultivares, não houve diferença na absorção de $\mathrm{K}$, exceto para a parte aérea no tratamento $\mathrm{NH}_{4}{ }^{+}$25:75 $\mathrm{NO}_{3}{ }^{-}$(Quadro 4). Para o Mg, somente foi observado um teor mais elevado

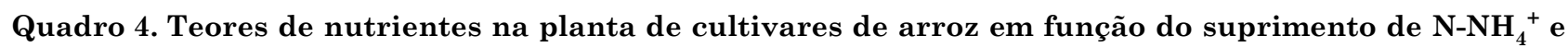
$\mathrm{N}_{-} \mathrm{NO}_{3}{ }^{-}$na solução

\begin{tabular}{|c|c|c|c|c|c|c|}
\hline \multirow{2}{*}{ Proporção } & \multicolumn{2}{|c|}{ Parte aérea } & \multicolumn{2}{|r|}{ Raiz } & \multicolumn{2}{|c|}{ Total absorvido } \\
\hline & IRGA 417 & Sasanishiki & IRGA 417 & Sasanishiki & IRGA 417 & Sasanishiki \\
\hline$\%$ & \multicolumn{4}{|c|}{$\longrightarrow \mathrm{N}, \mathrm{g} \mathrm{kg}^{-1} \longrightarrow$} & \multicolumn{2}{|c|}{$\longrightarrow \mathrm{N}, \mathrm{mg} / \mathrm{vaso}-$} \\
\hline $\mathrm{NH}_{4}^{+} 100: 0 \mathrm{NO}_{3}^{-}$ & $43,05 \mathrm{~b}^{(1)} \mathrm{A}^{(2)}$ & $41,48 \mathrm{ab} B$ & 16,10 a $\mathrm{B}$ & 19,19 a $\mathrm{A}$ & $70,62 \mathrm{bA}$ & $47,40 \mathrm{bB}$ \\
\hline $\mathrm{NH}_{4}^{+} 75: 25 \mathrm{NO}_{3}^{-}$ & 46,14 a $\mathrm{A}$ & 43,28 a B & 18,26 a B & 21,00 a $\mathrm{A}$ & $116,99 \mathrm{aA}$ & $66,54 \mathrm{aB}$ \\
\hline $\mathrm{NH}_{4}^{+} 25: 75 \mathrm{NO}_{3}^{-}$ & 45,97 a $\mathrm{A}$ & $39,78 \mathrm{~b} \mathrm{~B}$ & 17,50 a $\mathrm{A}$ & 19,66 a $\mathrm{A}$ & $85,18 \mathrm{bA}$ & $50,54 \mathrm{bB}$ \\
\hline & \multicolumn{4}{|c|}{ K, $\mathrm{g} \mathrm{kg}^{-1}$} & \multicolumn{2}{|c|}{$\longrightarrow \mathrm{K}, \mathrm{mg} / \mathrm{vaso}-$} \\
\hline $\mathrm{NH}_{4}^{+} 100: 0 \mathrm{NO}_{3}^{-}$ & 47,44 a $\mathrm{A}$ & 47,26 a $\mathrm{A}$ & 12,61 a $\mathrm{A}$ & $13,59 \mathrm{~b} \mathrm{~A}$ & $75,82 \mathrm{bA}$ & $51,40 \mathrm{aB}$ \\
\hline $\mathrm{NH}_{4}^{+} 75: 25 \mathrm{NO}_{3}^{-}$ & 47,62 a $\mathrm{A}$ & $45,25 \mathrm{ab} A$ & 15,34 a A & 20,64 a A & $118,17 \mathrm{aA}$ & $69,33 \mathrm{aB}$ \\
\hline $\mathrm{NH}_{4}^{+} 25: 75 \mathrm{NO}_{3}^{-}$ & 50,54 a A & $42,88 \mathrm{~b}$ B & 13,34 a $\mathrm{A}$ & $19,38 \mathrm{ab} \mathrm{A}$ & $91,04 \mathrm{bA}$ & $53,83 \mathrm{aB}$ \\
\hline & \multicolumn{4}{|c|}{$\mathrm{Ca}, \mathrm{g} \mathrm{kg}^{-1}$} & \multicolumn{2}{|c|}{$-\mathrm{Ca}, \mathrm{mg} / \mathrm{vaso}-$} \\
\hline $\mathrm{NH}_{4}^{+} 100: 0 \mathrm{NO}_{3}^{-}$ & $1,87 \mathrm{c} \mathrm{A}$ & $1,82 \mathrm{~b} \mathrm{~A}$ & $0,21 \mathrm{~b} \mathrm{~A}$ & 0,06 a $\mathrm{A}$ & $2,87 \mathrm{bA}$ & $1,82 \mathrm{aA}$ \\
\hline $\mathrm{NH}_{4}^{+} 75: 25 \mathrm{NO}_{3}^{-}$ & $2,34 \mathrm{~b} \mathrm{~A}$ & $2,21 \mathrm{ab} \mathrm{A}$ & $0,32 \mathrm{ab} \mathrm{A}$ & 0,08 a $\mathrm{A}$ & 5,56 aA & $3,07 \mathrm{aB}$ \\
\hline \multirow[t]{2}{*}{$\mathrm{NH}_{4}^{+} 25: 75 \mathrm{NO}_{3}^{-}$} & 3,18 a $\mathrm{A}$ & 2,53 a B & 0,61 a $\mathrm{A}$ & 0,22 a B & $5,71 \mathrm{aA}$ & $2,82 \mathrm{aB}$ \\
\hline & \multicolumn{4}{|c|}{$-\mathrm{Mg}, \mathrm{g} \mathrm{kg}^{-1}$} & \multicolumn{2}{|c|}{$-\mathrm{Mg}, \mathrm{mg} / \mathrm{vaso}-$} \\
\hline $\mathrm{NH}_{4}^{+} 100: 0 \mathrm{NO}_{3}^{-}$ & $4,99 \mathrm{ab} \mathrm{A}$ & 4,75 a $\mathrm{A}$ & 0,90 a $\mathrm{A}$ & 0,79 a $\mathrm{A}$ & 7,79 aA & 4,96 aA \\
\hline $\mathrm{NH}_{4}^{+} 75: 25 \mathrm{NO}_{3}^{-}$ & $4,13 \mathrm{~b} \mathrm{~A}$ & 4,55 a $\mathrm{A}$ & 1,07 a $\mathrm{A}$ & 0,75 a $\mathrm{B}$ & $10,27 \mathrm{aA}$ & 6,55 aA \\
\hline $\mathrm{NH}_{4}^{+} 25: 75 \mathrm{NO}_{3}^{-}$ & 5,57 a $\mathrm{A}$ & 4,12 a B & 1,04 a $\mathrm{A}$ & 0,83 a $\mathrm{A}$ & 9,91 aA & $4,78 \mathrm{aB}$ \\
\hline
\end{tabular}

(1) Médias seguidas por letras minúsculas iguais nas colunas não diferem entre si pelo teste do DMS (p >0,05). ${ }^{(2)}$ Médias seguidas por letras maiúsculas iguais nas linhas não diferem entre si pelo teste do DMS ( $p>0,05)$. 
no tratamento $\mathrm{NH}_{4}{ }^{+} 25: 75 \mathrm{NO}_{3}{ }^{-}$no tecido da parte aérea (Quadro 4). O teor de $\mathrm{Ca}$ foi alterado no tecido da parte aérea dos dois cultivares e nas raízes do IRGA 417 na medida em que a proporção de $\mathrm{NH}_{4}{ }^{+}$ aumentou, indicando que a absorção de Ca é alterada na presença de $\mathrm{NH}_{4}^{+}$. Para o Sasanishiki, não houve diferença entre os tratamentos para a absorção de cátions no tecido da raiz. Este comportamento está de acordo com a suposição de que o $\mathrm{NH}_{4}{ }^{+}$ocupe, em parte, os canais de transporte de baixa afinidade (LATs), como é o caso do Ca (Quadro 4); no entanto, este comportamento não ficou claro para $\mathrm{K}$ e para o $\mathrm{Mg}$, que, ao contrário do $\mathrm{Ca}$, são normalmente absorvidos contra um gradiente de concentração (Epstein \& Bloom, 2006).

Considerando o total absorvido do nutriente em função da biomassa total produzida e o teor do elemento no tecido vegetal, o estudo indica que as plantas supridas com $\mathrm{NH}_{4}^{+}$e $\mathrm{NO}_{3}^{-}$de forma combinada tiveram maior crescimento e, consequentemente, maior aproveitamento do N (Quadro 4), indicando a maior eficiência de absorção em relação às plantas em que o $\mathrm{N}$ foi fornecido isoladamente na forma de $\mathrm{NH}_{4}{ }^{+}$. O IRGA 417 apresentou também maior absorção total de $\mathrm{Ke}$ Ca com o suprimento combinado, e para o Sasanishiki não houve diferença entre o total absorvido dos nutrientes, indicando a variação entre a exigência nutricional das plantas (Quadro 4).

A importância de se considerar a absorção total dos nutrientes permite concluir com mais segurança sobre o efeito do suprimento combinado sobre o crescimento das plantas, ao contrário de se considerar somente a concentração do elemento no tecido como índice de eficiência de absorção. Nesse caso, a exigência nutricional de diferentes cultivares poderia ser considerada no manejo da fertilidade do solo.

$\mathrm{O}$ maior crescimento do arroz na presença de $\mathrm{NO}_{3}{ }^{-}$ e a redução na toxidez por $\mathrm{NH}_{4}{ }^{+}$indicam que o $\mathrm{NH}_{4}{ }^{+}$ não é a única e, ou, a principal fonte de $\mathrm{N}$ nas condições do solo alagado, conforme indicam trabalhos que consideram de forma isolada a elevação da concentração $\mathrm{NH}_{4}{ }^{+}$no ambiente anaeróbio e a perda rápida e total do $\mathrm{NO}_{3}^{-}$na disponibilidade de $\mathrm{N}$. Portanto, o $\mathrm{O}_{2}$ na camada superficial do solo ou na rizosfera do arroz, onde ocorre a proliferação de microrganismos nitrificadores e maior volume de raízes, deve ser considerado e a intensidade da nitrificação mais bem quantificada em estudos envolvendo o suprimento de $\mathrm{N}$ para essa cultura.

\section{CONCLUSÕES}

1. O suprimento combinado de $\mathrm{NH}_{4}{ }^{+}$e $\mathrm{NO}_{3}{ }^{-}$ proporcionou maior produção de parte aérea e raízes em relação ao $\mathrm{NH}_{4}{ }^{+}$suprido isoladamente, sendo a proporção $\mathrm{NH}_{4}{ }^{+} 75: 25 \mathrm{NO}_{3}{ }^{-}$a mais eficiente entre as testadas.
2. A toxidez causada pelo $\mathrm{NH}_{4}{ }^{+}$foi reduzida na medida em que aumentou a proporção de $\mathrm{NO}_{3}{ }^{-}$, indicando que o nitrato é uma importante fonte de $\mathrm{N}$ para a cultura do arroz.

3. O sistema radicular do arroz cresceu basicamente na camada de $0-10 \mathrm{~cm}$ em todos os tratamentos, mostrando uma distribuição superficial para os cultivares testados.

4. A presença de $\mathrm{NH}_{4}{ }^{+}$afetou os teores de Ca no tecido, porém sem efeito sobre o Mg e K.

5. A absorção total de nutrientes foi influenciada pela presença de $\mathrm{NH}_{4}{ }^{+}$e pela diferença genética entre os cultivares, mostrando variação na eficiência de absorção de nutrientes.

\section{LITERATURA CITADA}

ABICHEQUER, A.D. Morfologia e distribuição de raízes de arroz irrigado por inundação e sua relação com a absorção de nutrientes e o rendimento de grãos. Porto Alegre, Universidade Federal do Rio Grande do Sul, 2004. 66p. (Tese de Doutorado)

ARMSTRONG, W. Aeration in higher plants. Adv. Bot. Res., 7:225-332, 1979.

BRITTO, D.T. \& KRONZUCKER, H.J. Plant nitrogen transport and its regulation in changing soil environments. J. Crop Improvement, 15:1-23, 2005.

BRITTO, D.T. \& KRONZUCKER, H.J. $\mathrm{NH}_{4}{ }^{+}$toxicity in higher plants: A critical review. J. Plant Physiol., 159:567-584, 2002.

BRITTO, D.T.; SIDDIQI, M.Y.; GLASS, A.D.M. \& KRONZUCKER, H.J. Futile transmembrane $\mathrm{NH}_{4}{ }^{+}$ cycling: A cellular hypothesis to explain ammonium toxicity in plants. Proc. Nat. Acad. Sci., USA, 98:4255-4258, 2001.

CAO, W. \& TIBBITS, T.W. Response of potatoes to nitrogen concentrations differ with nitrogen forms. J. Plant. Nutr., 21:615-623, 1998.

CLAASEN, M.E.T. \& WILCOX, G.E. Effect of nitrogen form on growth and composition of tomato and pea tissue. J. Am. Soc. Hortic. Sci., 99:171-174, 1974.

COLMER, T.D. Aerenchyma and an inducible barrier to radial oxygen loss facilitate root aeration in upland, paddy and deep-water rice (Oryza sativa L.). Ann. Bot., 91:301-309, 2003.

CRAMER, M.D. \& LEWIS, O.A.M. The influence of nitrate and ammonium nutrition on the growth of wheat. (Triticum aestivum) and maize (Zea mays) plants. Ann. Bot., 72:359-365, 1993.

CRESTANA, S.; GUIMARÃES, M.F.; JORGE, L.A.C.; RALISCH, R.; TOZZI, C.L.; TORRENETO, A. \& VAZ, C.M.P. Avaliação da distribuição de raízes no solo auxiliada por processamento de imagens digitais. R. Bras. Ci. Solo, 18:365-371, 1994. 
DUAN, Y.H.; ZHANG, Y.L.; YE, L.T.; FAN, X.R.; XU, G.H. \& SHEN, Q.R. Responses of rice cultivars with different nitrogen use efficiency to partial nitrate nutrition. Ann. Bot., 99:1153-1160, 2007.

DUAN, Y.H.; ZHANG, Y.L.; SHEN, Q.R. \& WANG, S.W. Nitrate effect on rice growth and nitrogen absorption and assimilation at different growth stages. Pedosphere, 16:707-717, 2006.

EPSTEIN, E. \& BLOOM, A.J. Nutrição mineral de plantas: Princípios e perspectivas. 2.ed. Londrina, 2006. 401p.

FORDE, B.G. Nitrate transporters in plants: Structure, function and regulation. BBA-Biomembranes, 1465:219$235,2000$.

FORDE, B.G. Local and long-range signalling pathways regulating plant responses to nitrate. Ann. Rev. Plant. Biol., 53:203-224, 2002.

GIGON, A. \& RORISON, I.H. The response of some ecologically distinct plant species to nitrate and to ammonium nitrogen. J. Ecol., 60:93-102, 1972.

GUY, J. \& KIRK D. Rice root properties for internal aeration and efficient nutrient acquisition in submerged soils. New Phytol., 159:185-194, 2003.

HAYNES, R.J. \& GOH, K.M. Ammonium and nitrate nutrition of plants. Biol. Rev., 53:465-510, 1978.

HARADA, T.; TAKAKI, H. \& YAMADA, Y. Effect of nitrogen sources on the chemical components in young plants. Soil Sci. Plant Nutr., 14:47-55, 1968.

HOLLDAMPF, B. \& BARKER, A.V. Effects of ammonium on elemental nutrition of red spruce and indicator plants grown in acid soil. Comm. Soil Sci. Plant Anal., 24:19451957,1993

KIRK, G.J.D. \& KRONZUCKER, H.J. The potential for nitrification and nitrate uptake in the rhizosphere of wetland plants: A modeling study. Ann. Bot., 96:639-646, 2005 .

KIRK, G.J.D. Plant-mediated processes to acquire nutrients: Nitrogen uptake by rice plants. Plant Soil., 232:129-134, 2001.

KLUDZE, H.K.; DELAUNE, R.D. \& PATRICK Jr, W.H. Aerenchyma formation and methane and oxygen exchange in rice. Soil Sci. Soc. Am. J., 57:386-391, 1993.

KOSEGARTEN, H.; GROLIG, F.; WIENEKE. J.; WILSON, G. \& HOFFMANN, B. Differential ammonia-elicited changes of cytosolic $\mathrm{pH}$ in root hair cells of rice and maize as monitored by 2',7'-bis-(2-carboxyethyl)- 5 and (-6)carboxyfluorescein-fluorescence ratio. Plant Physiol., 113:451-461, 1997.

KRONZUCKER, H.J.; BRITTO, D.T.; DAVENPORT, R.J. \& TESTER, M. Ammonium toxicity and the real cost of transport. Trends Plant Sci., 6:335-337, 2001.
KRONZUCKER, H.J.; GLASS, A.D.M.; SIDDIQI, M.Y. \& KIRK, G.J.D. Comparative kinetic analysis of ammonium and nitrate acquisition by tropical lowland rice: Implications for rice cultivation and yield potential. New Phytol., 145:471-476, 2000 .

KRONZUCKER, H.J.; SIDDIQI, M.Y.; GLASS, A.D.M. \& KIRK, G.J.D. Nitrate-ammonium synergism in rice. A subcellular flux analysis. Plant Physiol., 119:1041-1045, 1999.

LOPES, S.I.G.; VOLKWEISS, S.J. \& TEDESCO, M.J. Desenvolvimento do sistema radicular do arroz irrigado. R. Bras. Ci. Solo, 18:273-278, 1994.

MALIK, A.I.; COLMER, T.D.; LAMBERS, H. \& SCHORTEMEYER, M. Aerenchyma formation and radial $\mathrm{O}_{2}$ loss along adventitious roots of wheat: Only the apical portion exposed to $\mathrm{O}_{2}$ deficiency. Plant Cell Environ., 26:1713-1722, 2003.

MURPHY, A.T. \& LEWIS, O.A.M. Effect of nitrogen feeding source on the supply of nitrogen from root to shoot and the site of nitrogen assimilation in maize (Zea mays L. cv. R201). New Phytol., 107:327-333, 1987.

PONNAMPERUMA, F.N. The chemistry of submerged soils. Adv. Agron., 24:29-96, 1972.

SMET, I.; ZHANG, H. \& BEECKMAN, T. A novel role for absicic acid emerges from underground. Trends Plant Sci., 11:434-438, 2006.

SPEER, M. \& KAISER, W.M. Replacement of nitrate by ammonium as the nitrogen source increases the salt sensitivity of pea plants. 2. Intercellular and intracellular solute compartmentation in leaflets. Plant Cell Environ., 17:1223-1231, 1994.

TROELSTRA, S.R.; WAGENAAR, R. \& SMANT, W. Nitrogen utilization by plant species from acid heathland soils. 1 . Comparison between nitrate and ammonium nutrition at constant low pH. J. Exper. Bot., 46:1103-1112, 1995.

TEDESCO, M.J.; GIANELLO, C.; BISSANI, C.A.; BOHNEN, H. \& VOLKWEISS, S.J. Análises de solo, planta e outros materiais. 2.ed. Porto Alegre, Universidade Federal do Rio Grande do Sul, 1995. 174p. (Boletim Técnico, 5)

TOBIN, A.K. \& YAMAYA, T. Cellular compartmentation of ammonium assimilation in rice and barley. J. Exper. Bot., 52:591-604, 2001.

WANG, M.Y.; GLASS, A.D.M.; SHAFF, J.E. \& KOCHIAN, L.V. Ammonium uptake by rice roots. II. Electrophysiology. Plant Physiol., 104:899-906, 1994.

WANG, M.Y.; SIDDIQI, M.Y.; RUTH, T.J. \& GLASS, A.D.M. Ammonium uptake by rice roots. I. Kinetics of ${ }^{13} \mathrm{NH}_{4}{ }^{+}$ influx across the plasmalemma. Plant Physiol., 103:1259$1267,1993$.

WOLT, J.D. Soil solution chemistry. New York, John Wiley \& Sons, 1994.

ZHU, Z.; GERENDAS, J.; BENDIXER, R.; SCHINNER, K.; TABRIZI, H.; SATTELMACHER, B. \& HANSEN, U.P. Different tolerance to light stress in $\mathrm{NO}_{3}{ }^{-}$and $\mathrm{NH}_{4}{ }^{+}$grown Phaseolus vulgaris L. Plant Biol., 2:558-570, 2000. 